\title{
Searching for the Direction of Multicultural Education from a Lifelong Education Perspective
}

\author{
Mi-Na Lee ${ }^{1}$ \\ ${ }^{1}$ Doctoral course in Cultural Studies, Chosun University, Korea, Imn4780@naver.com
}

\begin{abstract}
Due to recent globalization, immigrants have rapidly flowed in, and multicultural society is rapidly progressing. The multicultural society faced a new task of promoting coexistence with people from various cultural backgrounds and multicultural education began to attract more attention in this era. The existing multicultural education can be studied towards the direction of lifelong education and whether it has reached the educational objective of cultural pluralism or it can satisfy the universal educational needs. From this point of view, this study argues that when multicultural education is designed from the perspective of lifelong education, breaking away from the traditional educational paradigm, it can become an advantageous condition for achieving the educational objective of diverse objects along with cultural diversity. A multicultural lifelong education involves the expansion and integration of education throughout life and society, where learners and teachers participate. This makes it possible to understand and accept other cultures where learners choose and introspect by expanding the objects and areas of traditional education within various life aspects. In other words, in a pluralistic open society, the demand for universal education is emphasized to have citizenship qualities and capabilities and continuously develop them. This study will present a method of developing a multicultural lifelong education approach, a new paradigm of multicultural education to be developed in the future.
\end{abstract}

Keywords: Multicultural Society, Migrant Families, Lifelong Education, Approach

\section{Introduction}

Korea is entering a multicultural society because of globalization and the rapid influx of migrants due to the changes in the social environment at home and abroad. As of December 2019, there are about 2.5 million multicultural immigrants in Korea[1], leading to the country's multicultural socialization at a rapid pace in a short time. According to the Population and Housing Survey (2019), there are 60 cities, counties, and districts with more than 10,000 foreigners, and 55 cities, counties, and districts with foreigners more than $5 \%$ of the total population. The Education Ministry data also announced that the number of students from multicultural families each year exceeded 100,000 in 2017[2]. This is seen as the result of the full-fledged entry of children from multicultural families into school age, which has soared since the 2000s. The number of children from multicultural families is steadily increasing, not only those born in Korea but also those born in foreign countries and returning to Korea in middle school to follow their parents. In addition, the number of children born to foreign parents, such as children of foreign workers or children of overseas Koreans, is also increasing. The International Monetary Fund (IMF) report estimated that the proportion of the multicultural population would reach about $35 \%$ in 2050[3] A new approach and research on multicultural education are needed in line with the continuous increase in the proportion of the multicultural population. Multicultural education is routinely conducted

Received: July 15, 2020; 1st Review Result: September 7, 2020; 2nd Review Result: October 25, 2020 Accepted: November 30, 2020 
through various chapters of the social educational environment, such as families, colleagues, neighbors, churches, media, and schools. In other words, families, schools, media, peer groups, and other social environments should instill awareness of the multicultural society and play an educational role that leads to positive attitudes and behaviors. The purpose of multicultural education should be to have an attitude of mutual respect in a reality where different cultures coexist and help all members of the society to form a harmonious community, establish identity, and resolve prejudice[4][5]. Especially, at the human rights level, individual rights to education and learning should be guaranteed, the social level should resolve conflicts between cultures, and diversity and opportunities for creating new cultures should be provided. Given the complex heterogeneity and confusion, multicultural education needs a lifelong education approach as it moves beyond policies and systems into a society that meets in everyday life.

\section{Theoretical background}

\subsection{Understanding the Life-long Education}

The key to lifelong education is to nurture talent who will lead society based on knowledge in the 21 st century. Need someone with self-directed ability to select the information that can be utilized among the information, analyze and synthesize new information. Especially, the change in education during the Fourth Industrial Revolution should be centered on learning in which competence and character are emphasized so that human life can be centered while pursuing respect for human beings. Moreover, individuality, as well as educational publicness, should be emphasized around the community. The task is to look for the people who can develop their own culture and lifestyle independently, and people who can lead creative lives while working together with others. Also, the knowledge-based society features the revolution of information and communication, the globalization of competition, and the phenomenon of the advancement and diversification of demand. And learning where education takes place becoming more diverse, and work-learning is becoming more important, and it will expand quantitatively as learning outside of the institution is valued.

The terms of lifelong education are similar to those of lifelong education in English, life education in Japan, and life education in China. There are slight differences in each country, but the definition is the same. In the 21 st century, the word lifelong education has become an everyday and universal word. And it is deeply embedded in our lives and widely used. Modern society emphasizes the importance of national and social knowledge and establishes The law of Lifelong Education (1999) to create a knowledge-based society, and local governments strive to be recognized as a lifelong learning city. Also, due to the rapid development of information and communication technology, the world calls the global community transnationally and has one destiny community. Now, lifelong education and learning are becoming the lifestyles and survival methods of all human beings living in modern society, referred to as an information and knowledge society. To reactivate quickly due to new knowledge and information, we are constantly carrying out retraining, and we are also striving to improve the quality of human life by changing the new paradigm in the era of the fourth industrial revolution. Modern society is an information age, an era of diversification, and has characteristics of the period of lifelong education. In this era of various changes, effective, efficient, and sustainable technologies are needed to maintain long-term vitality in modern society. Therefore, from a lifelong education perspective, the role of lifelong educators is very important, and its scope and duties are also expanding, so lifelong education should be accepted as a paradigm for one survival. These learners are called Homo Eruditio.

The general characteristics of lifelong education are as follows.

First, lifelong education aims to improve the quality of life at the individual level and the social community level.

Second, lifelong education is the vertical integration of education conducted by an individual 
throughout his or her life, from birth to the grave.

Third, lifelong education is a horizontal integration of all institutions (such as schools, workplaces, media, libraries, volunteer organizations, etc.) and education conducted in schools, homes, society, and workplaces.

Fourth, lifelong education includes both planned and accidental learning.

Fifth, in lifelong education, efforts are made to equalize and expand educational opportunities throughout the entire people's lives. Sixth, in lifelong education, developmental tasks are important. Seventh, lifelong education tries to make general liberal education and professional education harmonize and balance. Eighth, lifelong education does not agree with schools monopolizing education and tries to find the meaning of school education from the perspective of lifelong education. Ninth, lifelong education tries to make society an educational environment. Number ten, lifelong education gives various and flexible forms, content, and methods of education, making it easy for anyone to access while coping with the needs of individuals and society. As such, all the characteristics of lifelong education are the goals of lifelong education itself. After all, the goal of lifelong education is to improve the quality of life for individuals, society, or human beings through lifelong education.

\subsection{Concept of Multicultural Education}

Multicultural education is designed to understand various cultures and to reduce prejudice against other cultures, such as race, ethnicity, social status, gender, religion, and ideology. The theory and practice of multicultural education have developed especially through the experience of Western society. Multicultural societies are largely divided into two types[6]. First, countries with homogeneous cultures, such as Britain, Germany, France, etc., face a multicultural society phenomenon with the influx of migrant workers, heterogeneous cultures, and new religions due to the globalization of capital and labor Second, the form of immigrant countries, such as the United States and Canada, consist of various races and cultures from the beginning of their founding[7]. Korea's multicultural society is developed similarly to the first type.

The multicultural education in France provided a systematic understanding of the real situation in which cultural diversity exists and the formation of attitudes to live in a multicultural society through long-term learning experiences. In addition, multicultural education in North America focused on shifting awareness of plurality in the educational system, providing them with appropriate and equitable educational opportunities regardless of gender, race, or religious background. In the United States, multicultural education originated from the civil rights protests of the 1960s, which tried to rule out discrimination in public facilities, housing, employment, and education[7]. The results of the civil rights movement had a significant impact on the educational system since the first ethnic group (AfricanAmerican), requiring schools and other educational systems and curricula to be reformed to reflect their history, experience, culture, and perspectives. Ethnic groups also pressed for control of schools and communities in the surrounding areas, and institutional education was required to revise textbooks to reflect the diversity of the people[8]. As a multicultural education in the West focused on basic attitudes in human life, environment, and relationships, it allowed people to have an open, critical, and unbiased attitude towards others by recognizing and respecting differences and values in different cultures and groups.

\subsection{Basic Perspective of Multicultural Education}

The commonality of multicultural education developed around the West is the reformative element that seeks to change school education for colored people or the cultural minority students[9]. In particular, the U.S. had an educational reform movement to improve the curriculum and education 
system so that all students from various social classes, races, ethnicities, and gender backgrounds can have equal educational opportunities. The educational reform movement aimed, first, to provide equal educational opportunities for all students. Second, the idea of American democracy is to realize equality, justice, and human rights. Third, the reform process pushed to reduce the discrepancy between democratic ideals and the actuality of schools and society as much as possible[10] (Kang Hyun-suk et al., 2010). In other words, multicultural education programs emerged in response to the needs of various groups, resulting in educational equality, for women, ethnic groups, minority languages, low-income groups, and the disabled. In addition, the difference between culture, race, social class, religion, and gender was recognized and accepted. Through this, they also taught democratic ideals of responsibility and justice, equality and democracy, which they argued could improve their quality of life in the name of reforming the educational system so that they had equal educational opportunities regardless of race, ethnicity, culture, religion and social class[11].

In the early 1990s, the Korean government opened its capital and labor markets when it declared globalization. Recently, the low birth rate and aging society have become inevitable due to the increase in the number of foreign workers, the increase in the number of foreign spouses due to international marriages, and the increase in the number of North Korean residents. If the multicultural society phenomena are not accepted, serious cultural conflicts and social problems can be triggered. From this point of view, it is necessary to consider a systematic lifelong educational perspective that multicultural education can proceed to the people. The content of education to be covered in multicultural education can be divided into two contexts.

First is the education and support for multicultural families and their family members. This education focuses on protecting the minority of multicultural families.

Second is the educational activities focused on improving multicultural understanding and awareness among the public. This is an education that seeks to change the majority on a more fundamental level by providing ordinary citizens and students with an understanding of minorities or a value education suitable for the era of globalization.

\subsection{Problems and Policy Directions of Childhood Education in Multicultural Families}

The difficulties faced by multicultural families including the problem of children's education are especially important. The discourse of multicultural education is essential to understand how children of multicultural families experience socialization and social learning in the process of adapting to Korean culture. A study on how children from multicultural families adapt to elementary school life suggests the need for active multicultural education[12]. It asked four questions about Kosian children's perception of Korean society. First, "Which country do you think you are from?" The answers varied from $10 \%$ Korea, $50 \%$ foreign countries, and $40 \%$ both from Korea and foreign countries. Second, "Which country do people around me think I am from?" They answered 20\% Korea, 50\% foreign countries, and 30\% both from Korea and foreign countries[13]. Third, "Have you ever bragged about your mother's country?" The answers include $50 \%$ no, $10 \%$ yes, and $40 \%$ others or no response. Fourth, "What if I talk about my mother's country in class?" They answered 20\% "I am not interested", 20\% "I'm interested, but I don't want to learn", 20\% "I want to learn more", 10\% "Other", and 30\% no response. These results represent that children from multicultural families have very confusing values in school life. Meanwhile, the high-frequency level of bullied children from multicultural families was due to ordinary children who were not provided with assimilation education. Also, the awareness of mixed blood was open to students who were provided with multicultural fairy tale education. This suggests a point of discussion that can break away from prejudice and discrimination against children from multicultural families. Nevertheless, there are still limitations to multicultural education. The perception of backward teachers and negative education in the mother's country has brought many 
difficulties in adapting to school. Korean children recognize and experience confusion in their perception of Korean society. Korean society should also establish multicultural values by breaking away from prejudice and discrimination caused by the national view of a single nation (www.nime.or.kr, the Lifelong Education Policy Forum). The education of children from multicultural families has the following characteristics. First, the development of the Korean language is delayed because of living with an immature immigrant mother in infancy. Second, there were also emotional disorders that showed a poor understanding of school classes and excessive passive or opposite violence or hyperactivity due to communication and cultural adaptation[14]. Third, they experienced group bullying (17.6\%), and school bullying (13.4\%), where their main reason was their mother is a foreigner (34.1\%) followed by poor communication (20.7\%). The biggest reason for bullying is to pretend to be arrogant (24.9 percent), which is different for children from multicultural families. Fourth, social problems also occur when children of multicultural families (87.0\%) enter middle and high schools and become more emotionally sensitive students give up school because they cannot endure prejudice and discrimination. In addition, there are various difficulties experienced by members of multicultural families.

First is the language and cultural conflict. Korean society needs to understand the culture of multicultural families, so there is a strong atmosphere to unilaterally integrate multicultural families into Korean culture.

The second is social prejudice. The phenomenon of Korean society is lacking in a multicultural tradition and has a pure-blood climate. Also, there are prejudice and discrimination against multicultural immigrants.

The third is social and cultural isolation. Multicultural migrants suffer from difficulties in language communication, inconvenience in living and cultural differences, have cases of family breakdown, and are alienated from information, resources, and employment.

Fourth, it is a matter of domestic violence. The prevailing perception of marriage between migrant women and Korean men is focused on the economic situation, thus, requires changing the Korean husbands' way of thinking.

Fifth, it is the confusion of children's identity confusion. Children of multicultural families experience a sense of psychological isolation and emotional alienation as they are ostracized by prejudice in Korean society.

Sixth, it is a matter of children's education. Children of multicultural families are having difficulties learning languages and they are limited in communication than those of ordinary families, leading to problems with poor learning.

Seventh, it is an issue of bullying. Most children of multicultural families experience bullying because of their different skin color and appearance.

Eighth, it is a poverty problem that connects generations. Due to the poor family environment and the social prejudice of multicultural families, they are alienated from schools and society, and as a result, they find it hard to escape from the current poverty.

\subsection{Role of Multicultural Lifelong Education}

Lifelong education refers to education conducted throughout the entire school and society from birth to death of an individual and it is an integrated and comprehensive system of education. In other words, it means lifelong education, which is beyond the age limitation and society. This is an education that goes beyond the existing ideological limitation of "school-centered education" in the sense of "realization of lifelong learning." Lifelong education is a concept similar to lifelong learning, which is self-directed learning for self-realization and satisfaction, but in the correct sense, it can be explained as a general curriculum that systematically establishes the learning process and environment so that lifelong learning can be achieved. In addition, the purpose of lifelong education is to enable lifelong 
learning during human existence and to extend education. The role of multicultural lifelong education can be found in the following contexts: the trend of globalization calls for virtually every country to be transformed into a multi-racial multicultural society. It should proceed to enable desirable social integration by knowing that coexistence and cooperation are universal social values, and tolerating and respecting cultural diversity as much as possible. To this end, members of the Korean society should enhance the level and capacity of understanding and accepting different cultures to recognize and practice them as "various cultural communities," and approach them as interactive education to change the majority and form a new community while protecting the cultural minority. Through this, various civil society organizations should minimize community conflicts through cooperation and lead the vision of a multicultural society[15]. In addition, role-sharing, cooperation, and coordination among educational entities should be carried out smoothly and a consumer-centered service support system should be established[16]. This will ensure equal educational opportunities by focusing on the construction of a civic community that pursues the common good by members of various ethnic, ethnic, and cultural backgrounds efficiently functioning in a democratic society and acquiring the knowledge, attitudes, and functions necessary for interaction, negotiation, and communication. In other words, multicultural lifelong education requires efforts to improve the overall educational conditions of society for growth and change throughout its entire life. Therefore, lifelong education in a multicultural society should be developed systematically by schools and educational institutions outside of schools.

\subsection{Community and Lifelong Education}

About 80 percent of the Korean Japanese occupation is mainly focused on agriculture. At that time, Korea's rural areas declined and collapsed beyond description due to its imperialist exploitation policy. Most of the farmers were peasants and their lives became more unstable after March 1st especially since the Honam region was rich in agricultural products and farmland. So early on, Japanese migration began, and oriental food companies began to take over. For these tenant farmers, the Farmers' Training Center was established to provide education for farmers. To improve agricultural management and farmers' status, a cooperative was established and a night school was established to teach the illiterate to write Hangeul and to count numbers and mathematics. During the period of farming and winter, he worked hard on rural finance by encouraging side jobs and also engaged in campaigns to improve the ills and lives of rural communities such as gardening and sanitation, prevention education of diseases, fighting, drinking, and superstition.

G. W. Avison founded a two-year agricultural unemployment school in her house in front of Supia Girls' School to train the workers in 1933. Qualification for admission should be those who receive a recommendation letter from the church pastor to which they belong and who have land to cultivate as an elementary school graduate and who have passed the written and oral exams. The contents of the education were processed agricultural products such as greens, peas, and sausages, and taught the Bible, and Korean history. Education for rural enlightenment and anti-literacy campaigns continued, and projects were operated through volunteers with the love of Christ.

In addition, social education programs for children, youth, and women were designed to help women overcome illiteracy by opening night schools to write and read the Bible. The contents of the education were Bible, Receiving, Geography, History, Japanese, Math, Korean, and Chinese.

To foster talented young workers and leaders, the Boys Scout, the Youth Detachment, has organized various education and training programs, including promoting national spirit.

In addition, he continued to devote himself to social education by holding Bible classes, Sunday schools, summer retreats, and lectures. In addition, the YWCA conducted various social reform campaigns and civic education for women in the region, including abstinence from drinking, antismoking, life improvement, rural enlightenment, and living conditions for women from other regions. 
In the early, the subjects were mainly taught in the Bible, Hangeul, arithmetic, and music, and in the 1930s, they introduced recipes, dyeing methods, sewing, etc. to educate the name of newspapers needed for daily life. In addition, the Bible breaks down superstition. In the 1970s, Saemaul education aimed at reforming the national spirit and increasing income, vocational skills education at various vocational training centers, And life-long education at the university began with youth organizations and KeaMyung University offering courses for women. In the 1980s, the Constitution included the national mandate for the promotion of lifelong education. In 1981, Korea Communications University was promoted to a four-year system. In 1982, the establishment of the Social Education Act and the establishment of an open college were implemented. In particular, various lifelong education opportunities were provided by opening social or lifelong education centers at each university. In the 1990s, the Education Reform Committee of the civilian government proposed the construction of an "open educational society, lifelong learning society" where anyone could receive the desired education anytime, anywhere. In the 2000 s, a lifelong learning festival was held in Gwangmyeong City in 2002 for the first time with the full implementation of the Lifelong Education Act, and such a festival aims to spread the lifelong learning culture around lifelong learning city. In March 2000, the Center for Lifelong Education of the Korea Educational Development Institute, a central organization dedicated to lifelong education, was launched and merged into the Institute for Lifelong Education in February 2008.

\subsection{Citizen Participation and Lifelong Education}

Civil education aims to foster the value of freedom to build individuals, criticism of communities that belong beyond the value of republics integrating organizations, and the ability to reflect on themselves.

Given the detailed purpose of the practice of creating a better world, self-change, and expansion of world knowledge and experience, it is necessary to establish a system of empathy and cooperation to enhance the status of civic education. This includes the contents of civic education, the professionalism of professors, the practical operation of the curriculum, the independence of educational institutions, including financial administration, and the enhancement of the status of civic education.

Civil education should lay the foundation for education based on practical and professional areas to cultivate the democratic capacity of consensus, solidarity, and practice as well as the enhancement of political literacy. It is necessary to emphasize practical education, including the discovery of areas of field activities and support programs that are common to the problem awareness of field activists, professors, and students, and the development of research capabilities. This is because civic participation education is fostered in the practical process of changing the framework of reasons and changing daily and social forms, away from automated and blind thinking. In this sense, the area of civic participation education can be summarized as follows

First, the realization of the equal right of learning for the cultivation of human dignity and equality and democratic civic qualities. As a dignified human being guaranteed by the Constitution and the Basic Law on Education, programs are emerging to create a lifelong education environment to guarantee equal learning rights, to guarantee opportunities for civic participation in education, and guarantee equal learning rights.

Second, it is the first step toward inclusive social realization. To realize an inclusive society where everyone is the owner and participates together, a place of learning is needed to foster self-respect and participate in a democratic society as self-directed citizens.

Third, it is required to secure the sustainability and driveability of lifelong education by promoting self-directedness. The self-directed ability achieved as a result of citizen participation in education serves as a driving force for continuous lifelong education participation for well-being and ultimate enjoyment of life with the initiative of the learner himself.

Fourth, the necessity of learning subject and learning environment reflects the needs and specificity 
of learners. The need for program reconstruction and environment creation is required to provide an opportunity to learn the 'citizen participation education' area of general lifelong education programs based on universality and minimum risk assumptions while meeting the best reality considering the learning characteristics and interests of disabled learners.

Fifth, it is the lifeization of participation through a life-oriented learning environment. Due to the lack of opportunities to learn civic participation education in the school curriculum, the need for systematic learning has emerged, and changes in values and attitudes pursued through civic participation education are required as learning activities reflecting the characteristics of continuous and repetitive practices learned in life that is not separated from life.

Sixth, the need for continuous and systematic program implementation is required. Compared to the importance of civic participation education, learning programs are lacking, and the need for education that presents the systematic direction of "citizen participation education" for disabled learners is required.

\subsection{The project Education for Children of Multicultural Families}

Policy tasks have been steadily reflected in the demand for education for children from multicultural families. In general, if you look at the subjects of education for children of multicultural families:

First, it is necessary to strengthen the capacity of parents at home.

Taking into account factors of the social capital of the family, such as the social, emotional, and physical development as well as intellectual development of students through the enhancement of the educational support capacity of multicultural parents through the promotion of various information on children's education of multicultural parents, the development of families' psychological support roles for Korean fathers and children, and the formation of a positive attitude toward mothers to help them to be exposed to the language and culture of their mothers from an early age.

Second, it is necessary to strengthen the competence of teachers in schools.

There are ways to raise teachers' interest in students from multicultural families, expand opportunities for mutual exchanges with these families, expand training opportunities to ease the burden on multicultural education for teachers, consult students related to multicultural education, and share information on teaching strategies. According to statistics such as strengthening peer groups, the number of children from multicultural families surveyed was not as high as expected. Programs that induce frequent contact with peers from an early age are effective

Third, need to enhance the role of the media.

Efforts will be needed to avoid sensational reporting attitudes toward multicultural families, restore balance, spread and share cases of successful multicultural families, and broadcast them in programming programs that can enhance understanding of foreign social-economic realities and cultural traditions.

Fourth, civic groups need to strengthen their educational capabilities.

There are efforts to protect human rights to guarantee the right to learn and induce middle and high school students to voluntarily and actively participate in learning volunteer work.

Fifth, necessary to strengthen the capacity of the parties' self-help meetings.

In the long period, for the advancement of the second and third generations of migrants into society and coexistence with political residents, policy support is needed to strengthen the economic, cultural, and political independence of immigrant families based on the ideology of multicultural citizenship.

\section{Results}

The recent globalization has led to a rapid influx of migrants, which has led to the rapid progress of multicultural society. Multicultural societies had a new task of promoting coexistence with people from 
various cultural backgrounds, and multicultural education in this era began to draw more attention. In this line, the study argues that multicultural education can only be a favorable condition for achieving the educational objective of various objects along with cultural plurality when it is planned from the perspective of lifelong education, breaking away from the traditional educational paradigm. From this view, the study argues that multicultural education can only be a favorable condition for achieving the educational objective of various objects along with cultural plurality when it is planned from the perspective of lifelong education, breaking away from the traditional educational paradigm. Multicultural life-long education involves the lifelong expansion and integration of education, as well as learners and educators. This study proposes a way to develop multicultural lifelong education in the form of a new paradigm of multicultural education that will be processed in the future. Through this study, I would like to argue for a way to develop multicultural lifelong education in the form of a new paradigm of multicultural education that will be processed in the future.

\section{Conclusions}

This study breaks away from the traditional education paradigm and approaches comprehensive education for all subjects with cultural plurality only when multicultural education is planned from the perspective of lifelong education. Multicultural lifelong education is intended to help people understand and accept other cultures by expanding the scope of traditional education and the overall life of education through the extension and integration of education. Future tasks for multicultural lifelong education are as follows.

First, the basis and system for promoting multicultural education should be clearly defined by the law of Multicultural Education Promotion. The law of Multicultural Families Support is limited to multicultural families, such as migrant women and children, and it is highly lacking as a basis for promoting multicultural education as it focuses on awareness improvement education. Multicultural education should be conducted for all members of the society, including foreigners, refugees, and the North Korean defectors, so it could focus on coexisting with the whole society and understanding the diversity of race, ethnicity, religion, etc. The presented educational philosophy and goals are suitable for a multicultural society to establish a systematic multicultural education promotion system stably.

Second, lifelong education needs to be actively utilized in the lifelong education promotion system by developing multicultural education programs in various ways and types that consider the characteristics of adult learners, such as age, occupation, and region. The Ministry of Gender Equality and Family develops and provides the public, including ordinary people, facility workers, and office workers, programs on understanding the multicultural society. However, the effects are limited because of the manner the programs were conducted, which was either online or collective. The government should actively consider ways where anyone can easily access and participate in programs in connection with the local lifelong education promotion system, such as the Happiness Learning Center currently operated by local governments.

Third, support for teacher training on multicultural competency should be strengthened. With the rapid increase of multicultural students, the role of education in preparing for social integration and a mature multicultural society should be emphasized. In addition, customized education support is needed in response to the increase in the number of multicultural students of various types, including refugees and children of illegal immigrants. Therefore, the government should promote multicultural understanding education by enhancing the expertise of teachers in preschool, elementary and middle schools, and strengthening the teachers' ability to teach multicultural students, such as creating a multicultural school environment, supporting Korean language education, supporting education for middle-of-the-road and foreign students, and supporting counseling for adolescents.

Fourth, policies for multicultural education should be operated more flexibly and autonomously 
depending on regional characteristics. While operating schools divided into existing preparatory schools, multicultural-focused schools, and multicultural kindergartens, the government should improve the limitations of not properly reflecting regional characteristics and promote multicultural education autonomously through the curricula, creative experience activities, and after-school programs depending on the characteristics and school conditions of each region.

In conclusion, multicultural education is an area within the context of the purpose and method of lifelong education, and the convergence of the two areas is desirable and hopeful. Multicultural education is an important content area of lifelong education, and multicultural lifelong education is a key area. In other words, multicultural lifelong education should be equipped with civic qualities and capabilities in a pluralistic open society. In addition, multicultural education should be sought from a lifelong education perspective being a universal education that must be pursued and should continually develop.

\section{References}

[1] Statistical Office, kostat.go.kr, July 15 (2020)

[2] Ministry of Education, www.moe.go.kr, July 15 (2020)

[3] Korea Future Report, http://www.knsseoulnews.com, July 15 (2015)

[4] Jong Nam Seo, A Study of the Use of Multicultural Terminologies in Korea: Based on Facts and FGI on Related Persons, Journal of Education \& Culture, (2010), Vol.16, No.2, pp.145-168, DOI: 10.24159/joec.2010.16.2.145

[5] Jong Im Ahn, The Linkage between Multicultural Education and Media Literacy Education: Reviewing and seeking the Multicultural Status in the wake of the increase in marriage migrant women and migrant workers, Generalized Women's Research, (2011), Vol.26, No.1, pp.1-30.

[6] Min Kyung Lee, Analysis of European Diploma in Intercultural Competence(EDICC): Implication on the multicultural education in Korean University, Contemporary Society and Multiculture, (2014), Vol.4, No.2, pp.1-35.

[7] Ji Yeon Song, Development and Application of Multicultural Education Program in Middle School: Focused on Creative discretionary activities, Graduate School of Korean National University of Education, Master Thesis, (2010)

[8] James A. Banks, Multicultural Education, and Curriculum Transformation, The Journal of Negro Education, (1995), Vol.64, No.4, pp.390-400, DOI: https://doi.org/10.2307/2967262

[9] Kyung Hwan Mo, Sun A Kim, A Critical Analysis of Global Citizenship in 2015 Revised Elementary Social Studies Curriculum, Theory, and Research in Citizenship Education, (2018), Vol.50, No.1. pp.29-51, DOI: $10.35557 /$ trce.50.1.201803.002

[10] Hyun Suk Kang, Hyun Mi Cho, Jeong Hee Jung, Ji Young Lim, Kwang Suk Lee, Kyung Sik Kim, Che Moon Lee, Choon Kyung Kim, Development and Application of Multicultural Counseling Center Model to Solve the Polarization of Multicultural Society, The Korea Research Foundation (NRF), (2010)

[11] M.T. Gumbo, Multicultural education and its politics, South African Journal of Education, (2001), Vol.21, No.4, pp.233-246.

[12] Jun Sung Park, Hye Jung Ahn, Tae Yun Jung, Life-Stress Faced by Elementary School Students from Multi-Cultural Families and Its Influence on Their Elementary School Adjustment: The Moderating Effects of Self-Esteem, ParentChild Relations, and Peer Relations, Stress (KSSM), (2013), Vol.21, No.1. pp.51-60, UCI: G704002182.2013.21.1.003

[13] Young Hwa Park, Focusing on Korean language learning materials for children under the age of 6 from multicultural families, Hanyang University Graduate School, Master Thesis, (2013)

[14] Ki Dae Hong, Investigation into the Future Direction of Multicultural Education to Decrease Bias against Multicultural 
Students: A Case Study of Kwangju · Jeonnam Region, Journal of The Korean Association of Regional Geographers, (2011), Vol.17, No.4, pp.381-394, UCI: G704-000607.2011.17.4.001

[15] Sun Woo Kim, A Study on the Method of Korean Culture Education for Foreigners, Dongshin University graduate school, Master Thesis, (2014)

[16] Soo Jung Kim, A Study on the Korean Culture Education of Migrant Women Using the Media, Dongguk University graduate school, Master Thesis, (2012) 